Conference Presentation

\title{
"Ultra-high Dilution" 1994 revisited 2014: Follow up of experiments and theories
}

\author{
P C Endler'1, Jurgen Schulte², Beate Stock-Schroeer ${ }^{3}$ \\ ${ }^{1}$ Interuniversity College for Health and Development Graz / Castle of Seggau, Austria. Email: college@inter- \\ uni.net \\ ${ }^{2}$ Faculty of Science, University of Technology, Sydney, Australia \\ ${ }^{3}$ Karl and Veronica Carstens-Foundation, Essen, Germany
}

\begin{abstract}
Background: "Research in ultra-high dilutions, and the interaction of ultra-high dilutions and living systems, has reached a level of quality and popularity that it is about to be taken seriously by current ... sciences ..." the editors wrote in their introduction to "Ultra High Dilution. Physiology and Physics", published by Kluwer (now Springer) in 19941. Back then, this anthology assembled contributions of leading scientists in fundamental and clinical research on homeopathy. Over the following two decades, it became widely quoted within the homeopathic community and also known in other research communities.
\end{abstract}

Aim: To re-visit and review the 1994 studies in biology, physics, biophysics and clinics from the perspective of 2014 .

Methods: As a rule, the original authors from 1994 or closed laboratory colleagues were asked to contribute papers covering their research efforts and learnings in the period from1994 up to 2014. These contributions were a) edited and cross-referenced and b) peer reviewed via the Elsevier Electronic System in preparation of a special issue of the journal "Homeopathy", London, to appear in October 2015.

Results: Part 1 (Biology) includes chapters

- on dose-dependent hormesis effects in low and very low doses by Menachem Oberbaum, who was also the author on this topic in 1994;

- on further results on the "classical" model with wheat and an ultra high dilution (UHD) of a silver salt by Waltraud Scherer-Pongratz, also author in 1994, et al.; on the model with highland amphibians and an UHD of the hormone thyroxine by Christian Endler, also author in 1994, et al.; and on a new model derived from the latter two, combining wheat and a plant hormone by Scherer-Pongratz and Endler;

- on a botanical and a zoological survey on high dilution research by the new contributors Tim Jäger, Stephan Baumgartner et al. and Leoni Bonamin et al., as well as a survey on immunological research by Bernard Poitevin, also author in 1994.

\section{OPEN ACCESS}

Cite as: Endler PC, Schulte J, Stock-Schroeer B. "Ultra-High Dilution” 1994 revisited 2014. Follow up of experiments and theories. Proceedings of the XXIX GIRI Meeting; 2015 June 3 - 5; Verona (Italy). Int J High Dilution Res. 2015; 14(2): 47-48 
- on UHD research from the laboratory of Madeleine Bastide, decedée, now pursued by Bonamin, and from the laboratory of Jacques Benveniste, decedé, now pursued by Yoléne Thomas;

Part 2 (Biophysics) includes chapters

- on effects of homeopathic medicines in closed vials by Roeland van Wijk, also author in 1994, et al.;

- on electromagnetic and magentic vector potential bio-information and water by Cyril Smith, also author in 1994;

Part 3 (Physics) includes chapters

- on investigation topics, models and theories presented by various authors in 1994, followed up by Jurgen Schulte;

- on experimental methods by Schulte, also author in 1994;

- $\quad$ on the recent discussion on the theory of entanglement by Schulte

Part 4 (Clinics) includes chapters

- $\quad$ on provings of UHDs on healthy volunteers by Harald Walach, also author in 1994;

- on a review by Robert Mathie of clinical research on homeopathy, as a follow-up to Max Haidvogl's contribution (Haidvogl being happily retired) referring to Klaus Linde in 1994.

Furthermore,

- a contribution on quality and standards of reporting in homeopathy research was added by Beate Stock-Schroer,

- a bibliographic survey on repetitions of experiments on UHDs by Endler et al. was included,

- the outlook on "preliminary elements of a theory on UHDs" from 1994 was updated by the editors;

- and Marco Righetti, as well as Peter Fisher, also contributors in 1994, wrote prefaces.

Conclusion: "Ultra High Dilution revisited", the special issue of "Homeopathy", October 2015, may be seen as a "buena vista social club" of homeopathy researchers 1994 (luckily supported by younger colleagues), as a disclosure of new results on the old models (what happened between 1994 and 2014?), as well as a general survey on the state of UHD research.

Keywords: Ultra-high dilution, homeopathy, research

(C) International Journal of High Dilution Research.

Not for commercial purposes.

\section{OPEN ACCESS}

Cite as: Endler PC, Schulte J, Stock-Schroeer B. "Ultra-High Dilution" 1994 revisited 2014. Follow up of experiments and theories. Proceedings of the XXIX GIRI Meeting; 2015 June 3 - 5; Verona (Italy). Int J High Dilution Res. 2015; 14(2): 47-48 